\title{
Deuxième voyage du sieur Paul Lucas dams le Levant (octobre 1704-septembre 1708), présenté par Henri Duranton
}

\section{Franco Piva}

\section{(2) OpenEdition}

1 Journals

\section{Edizione digitale}

URL: http://journals.openedition.org/studifrancesi/36156

DOI: $10.4000 /$ studifrancesi.36156

ISSN: 2421-5856

\section{Editore}

Rosenberg \& Sellier

\section{Edizione cartacea}

Data di pubblicazione: 1 juillet 2005

Paginazione: 163-164

ISSN: 0039-2944

\section{Notizia bibliografica digitale}

Franco Piva, «Deuxième voyage du sieur Paul Lucas dams le Levant (octobre 1704-septembre 1708), présenté par Henri Duranton», Studi Francesi [Online], 145 (XLIX | I) | 2005, online dal 30 novembre 2015, consultato il 18 avril 2021. URL: http://journals.openedition.org/studifrancesi/36156 ; DOI: https://doi.org/10.4000/studifrancesi.36156

Questo documento è stato generato automaticamente il 18 avril 2021.

\section{cc) $($ ) $\ominus$}

Studi Francesi è distribuita con Licenza Creative Commons Attribuzione - Non commerciale - Non opere derivate 4.0 Internazionale. 


\title{
Deuxième voyage du sieur Paul Lucas dams le Levant (octobre 1704-septembre 1708), présenté par Henri Duranton
}

\author{
Franco Piva
}

\section{NOTIZIA}

Deuxième voyage du sieur Paul Lucas dams le Levant (octobre 1704-septembre 1708), présenté par Henri duRANTON. Publications de l'Université de Saint-Etienne, 2002, («Lire le Dixhuitième siècle»), pp. 239.

1 Presentiamo con piacere anche se in ritardo questo volume, curato da Henri Duranton e apparso in una collana, da lui stessa fondata e diretta, che au fil des ans ha rimesso in circolo tutta una serie di testi settecenteschi poco, o punto noti, che hanno reso un grande servizio a quanti si occupano di Settecento, in particolare di quel Settecento meno conosciuto sul quale da alcuni decenni s'è appuntata con sempre maggiore insistenza l'attenzione degli studiosi; una collana che per ciò stesso meriterebbe di essere meglio conosciuta e più largamente diffusa. Una chiara conferma è data da questo Deuxième voyage au Levant che l'antiquaire du Roi Paul Lucas compì dal 1704 al 1708 dapprima nella "Natolie, la Caramanie et la Macédoine" per riprendere il sottotitolo del primo volume, poi l'Egitto, passando per Gerusalemme e più in generale per quella che all'epoca era chiamata la "Barbarie" di cui il secondo volume propone un'interessante ed accurata descrizione. Lucas, sempre per ordine di Luigi XIV, negli anni precedenti aveva fatto un altro viaggio dalle cui note Baudelot de Dairval aveva tratto un testo che era apparso nel 1708. Dalle note prese da Lucas nel corso di questo suo secondo viaggio, condotto in condizioni ancora più precarie, tanto che i suoi amici lo avevano dato per disperso, l'orientalista Etienne Fourmont trasse una relazione, apparsa nel 1712, di straordinario interesse. "La lecture des voyages est toujours utile", faceva osservare Formont nella sua Préface. È per altro verso noto il ruolo che i viaggi e le relazioni che viaggiatori come Tavernier, Chardin e Lucas appunto hanno lasciato, 
ebbero non solo per una migliore conoscenza, in questo caso dei paesi del Vicino Oriente, ma anche per una salutare messa in discussione della visione che del mondo, della storia e dell'uomo i Francesi avevano alla fine del Seicento. Parlando degli effetti che la "lecture des voyages" ha sui lettori, Formont faceva notare che essa è "capable seule d'instruire les hommes, des coutumes et des manières d'agir de leurs semblables dans des pays différents du leur" e che essa "ne manque jamais de délivrer leur esprit de la plupart de ces opinions vulgaires que l'ignorance ou l'éducation y font naître". Questo Voyage è la riprova di quanto Formont affermava all'inizio del Settecento e di quanto gli storici delle idee hanno ribadito all'inizio del Novecento. Se, corne faceva ancora osservare Formont, "les mahométans [passaient] parmi les chrétiens pour des gens ou aveuglés ou stupides et incapables de penser", senza nessuna "teinture de logique ou de métaphysique", se, in altri termini, i cristiani pensavano che "la philosophie, la rhétorique, les humanités [étaient] exilées de chez eux", il resoconto di Lucas dimostra che "ces pensées [étaient] non seulement grossières, mais injustes et très déraisonnables". La cultura araba, e maomettana in genere, dalle pagine di Lucas esce nettamente rivalutata, così come rivalutata esce la civiltà che quei popoli hanno saputo costruire. $\mathrm{Fu}$ dal confronto con realtà come quella proposta da Lucas che l'Europa imparò ad aprirsi e ad interrogarsi; ed è dalla lettura di testi come questo che anche noi possiamo imparare a capire meglio le trasformazioni che l'Europa conobbe tra la fine del Seicento e l'inizio del Settecento Per cui ad iniziative come questa di Henri Duranton non si può che applaudire con convinzione. 